\title{
IDENTIFICATION OF CHEMICAL HETEROGENEITY WITH THE USE OF COLOUR METALLOGRAPHY AND EDS OF THE AICu4Mg1 ALLOY
}

\author{
Jaroslava SVOBODOVÁ, Irena LYSOŇKOVÁ, Pavel KRAUS \\ Jan Evangelista Purkyne University, Ústí nad Labem, Czech Republic, EU, \\ jaroslava.svobodova@ujep.cz, irena.lysonkova@ujep.cz, pavel.kraus@ujep.cz
}

https://doi.org/10.37904/metal.2020.3611

\begin{abstract}
Aluminum alloys, which have a higher content of alloying elements, are prone to crystal segregation. This segregation will significantly affect the physical, mechanical and chemical properties of these alloys. Crystal segregation is essentially micro-scale chemical heterogeneity and occurs during alloy crystallization. The experimental work described in the paper is focused on the identification of chemical heterogeneity in the alloy EN AW-2024 (AICu4Mg1). It is one of the most important aluminum alloys, which is intended for use in the aerospace and military sectors in the fuselage applications of such areas as wing tensioning structures and elements. To refinement of the structure and improve the mechanical properties, the alloy was inoculated with AITi3B1 in various concentrations and the effect of this inoculant on the refinement of the structure was studied. The formation of crystal segregation in Al alloys cannot be prevented, but its extent can be influenced, or it can be suppressed by the correct choice of parameters using heat treatment, which was applied in this experiment as well. Optical microscopy and EDS analysis were used to evaluate experimental samples, by which the distributions of individual elements and phases were documented.
\end{abstract}

Keywords: AlCu4Mg1, chemical heterogeneity, AITi3B1, heat treatment, colour etching

\section{INTRODUCTION}

Copper is considered one of the most important elements in aluminum alloys, thanks to the high solubility in aluminum and the reinforcing effect. Strengthening occurs at low temperatures by heat treatment, at high temperatures it occurs to the creation of alloys with iron, manganese, nickel, etc. Many industrial aluminum alloys contain copper either as a basic admixture or act together with other alloying elements in the amount of $1-10 \mathrm{wt} \%$. The equilibrium phases in the Al-Cu system on the side of both metals creates unrestricted solid solutions $(\mathrm{Cu})$ and $(\mathrm{Al})$ with a cubic face-centered lattice. The maximum solubility of copper in solid aluminum solution under equilibrium conditions is 2.48 at\% ( $5.7 \mathrm{wt} \%) \mathrm{Cu}$ at the eutectic temperature $548.2^{\circ} \mathrm{C}$ [1]. The effort of all leading foundries is to get to the castings with the finest structure. The reason for this trend is the fact that castings with a fine structure have better mechanical properties, both strength and plastic $\left(R_{m}, R_{e}, A\right)$, than castings whose structure is coarse-grained. Grain refinement has been applied since the discovery of the beneficial effect of the inoculation nuclei addition for heterogeneous nucleation [2,3]. The fine structure is necessary to eliminate column crystallization, hot cracking associated with insufficient metal reach during volume changes at the crystallization with interdendritic porosity, or to prevent cold cracking, which is associated with low values of ductility of the material in the cast state [4]. The elements that refine the structure due to the formation of crystalline nuclei are: $\mathrm{Ti}, \mathrm{B}, \mathrm{Zr}$, Sc. The addition of one of these elements also changes the cooling curve of the alloys. The melting points of all listed applied elements, which form the relevant intermetallic phases, are much higher than the melting temperatures of foundry $\mathrm{Al}$ alloys. This means that when we add the appropriate master alloy to the melt, e.g. AITi5B1, melting of Al occurs, but not to the melting of the intermetallic phases. Therefore, it is important that the applied master alloys, with the aim to refine the 
structure, had, in addition to the required chemical composition, also a suitable size of the respective intermetallic particles and a quality [1,5]. A common industry standard is the addition of a grain refiner based on AITi, AITiB, AITiC, AIB4C [6].

Aluminum alloys with a higher content of alloying elements are very prone to the formation of crystal segregation, which significantly affects the mechanical, physical and chemical properties of these alloys. Crystal segregation is called micro-scale chemical heterogeneity and occurs during crystallization. Crystallization of alloys does not take place at a specific temperature, as is in the case of pure metals, but within a certain temperature range. As the melt cools, different areas are formed within the dendritic cells that differ in chemical composition. In general, crystal segregation can be defined as chemical heterogeneity resulting from the crystallization of an alloy that is enriched or depleted in alloying elements and impurities that segregate unevenly over the entire surface area of the dendrites. The formation of crystal segregation in aluminum alloys rich in alloying elements and admixtures cannot be prevent, its extent can only be influenced and suppressed by the correct choice of heat treatment parameters. To suppress crystal segregation, the castings are subjected to heat treatment. It is a diffusion process in which the chemical composition of the alloy is balanced and take places the uniformization of its structure.

The scientific goal of this paper is to analyze the structure of a specific alloy AlCu4Mg1 (EN AW-2024) in connection with the practice using optical microscopy (color metallography) and SEM/EDS inoculated with AITi3B1 and heat-treated (homogenization annealing). This is a solution to a specific case of alloy application, inoculation and heat treatment parameters in practice. This experiment is part of a wider research, which is focused on increasing the mechanical properties of this particular alloy by inoculating AITi3B1 and AITi5B1 in various concentrations with subsequent heat treatment under specific required conditions. In this paper we present the results of $\mathrm{AlCu} 4 \mathrm{Mg} 1$, inoculated with AITi3B1 in a concentration of $0 ; 0.3 ; 3 \mathrm{wt} \%$ (the experiment is of course much more extensive, but for the purposes of this paper only these concentrations and conditions are presented).

\section{EXPERIMENTAL}

AICu4Mg1 alloy supplied by the manufacturer with a chemical composition according to the standard ČSN EN 573-1 Aluminum and aluminum alloys - Chemical composition and types of formed products - Part 1: Numerical designation was used for the preparation of castings. The aluminum alloy was melted in an induction furnace at $720^{\circ} \mathrm{C}$, the furnace temperature was captured using a digital thermometer with an accuracy of $\pm 2{ }^{\circ} \mathrm{C}$. The melt was treated during melting by refining salt and the smear was shut down from the melt surface. At the end of the melting process, AITi3B1 wire was added to the alloy in concentrations $0 ; 0.3 ; 3 \mathrm{wt} \%$. The heat treatment parameters were set: heating of castings $500{ }^{\circ} \mathrm{C}$, holding at a temperature of $360 \mathrm{~min}$ and cooling to water, the subsequent ageing took place naturally. The chemical composition of the prepared alloys was determined with spectrometric analysis on device Tasman Q4 and is listed in Table 1.

Table 1 Chemical composition of experimental AICu4Mg1 alloy (wt\%)

\begin{tabular}{|c|c|c|c|c|c|c|c|c|c|c|}
\hline $\begin{array}{c}\text { Element/ } \\
\text { Sample }\end{array}$ & $\mathbf{S i}$ & $\mathbf{F e}$ & $\mathbf{C u}$ & $\mathbf{M n}$ & $\mathbf{M g}$ & $\mathbf{C r}$ & $\mathbf{N i}$ & $\mathbf{Z n}$ & $\mathbf{T i}$ & $\mathbf{A l}$ \\
\hline 1 & 0.480 & 0.062 & 5.049 & 0.010 & 0.460 & $<0.002$ & $<0.002$ & 0.255 & 0.043 & residue \\
\hline 2 & 0.479 & 0.077 & 4.874 & 0.246 & 0.216 & $<0.002$ & $<0.002$ & 0.261 & 0.117 & residue \\
\hline 5 & 0.518 & 0.071 & 4.477 & 0.271 & 0.342 & $<0.002$ & $<0.002$ & 0.256 & 0.157 & residue \\
\hline 6 & 0.451 & 0.062 & 4.217 & 0.075 & 0.266 & $<0.002$ & $<0.002$ & 0.251 & 0.125 & residue \\
\hline 11 & 0.500 & 0.084 & 5.350 & 0.267 & 0.071 & $<0.002$ & $<0.002$ & 0.258 & 0.234 & residue \\
\hline 12 & 0.541 & 0.072 & 5.141 & 0.033 & 0.750 & $<0.002$ & 0.0024 & 0.242 & 0.176 & residue \\
\hline
\end{tabular}




\subsection{Optical microscopy analysis}

Metallographic experimental samples (Figures 1 -12) were prepared from castings by the classical procedure of metallographic samples preparation (cutting, grinding, and polishing) and subsequently color etched. Color etching was performed with a solution of potassium permanganate $\mathrm{KMnO} 4$ in alkaline medium of sodium hydroxide $\mathrm{NaOH}$ for the time 40 seconds. Thus prepared samples were observed and scanned by confocal laser microscope.

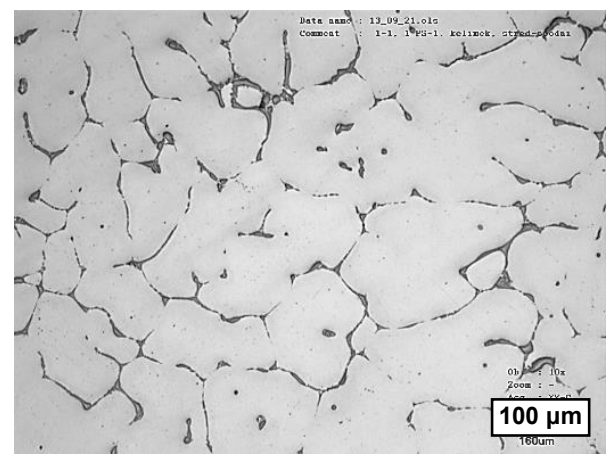

Figure 1 Microstructure of the alloy AlCu4Mg1 $0 \mathrm{wt} \%$ of AITi3B1, unetched, sample 1

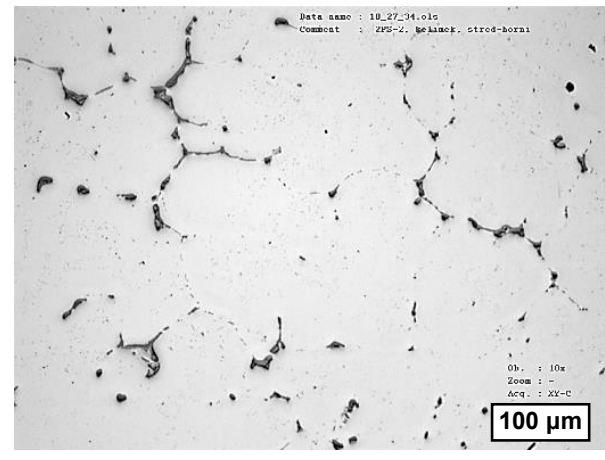

Figure 3 Microstructure of the alloy AlCu4Mg1 0 wt $\%$ of AlTi3B1, heat-treated, unetched, sample 2

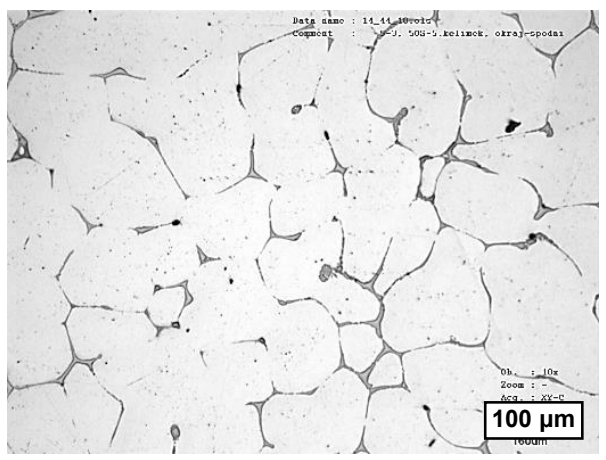

Figure 5 Microstructure of the alloy $\mathrm{AlCu} 4 \mathrm{Mg} 1$ $0.3 \mathrm{wt} \%$ of AITi3B1, unetched, sample 5

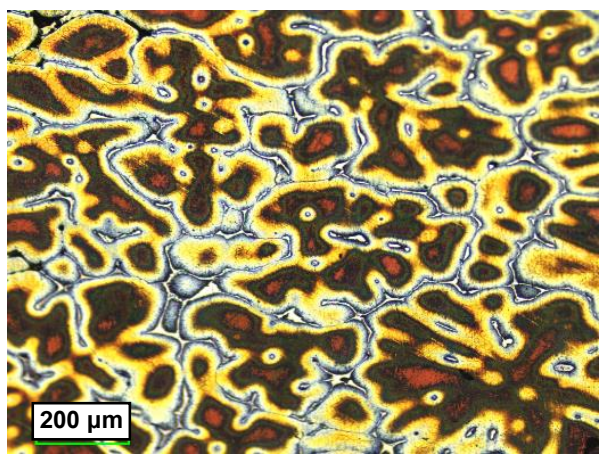

Figure 2 Microstructure of the alloy AlCu4Mg1 $0 \mathrm{wt} \%$ of AITi3B1, etched, sample 1

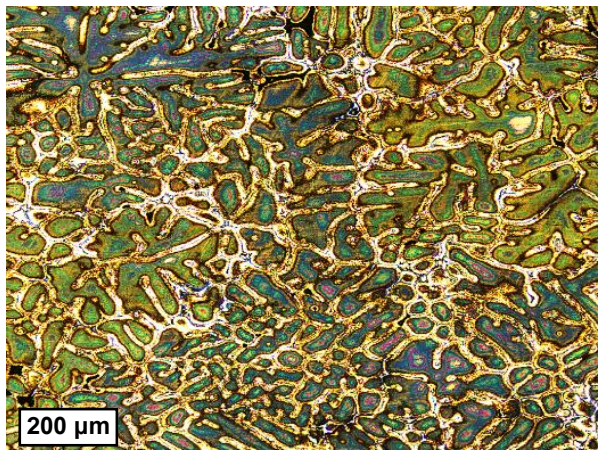

Figure 4 Microstructure of the alloy AICu4Mg1 $0 \mathrm{wt} \%$ of AITi3B1, heat-treated, etched, sample 2

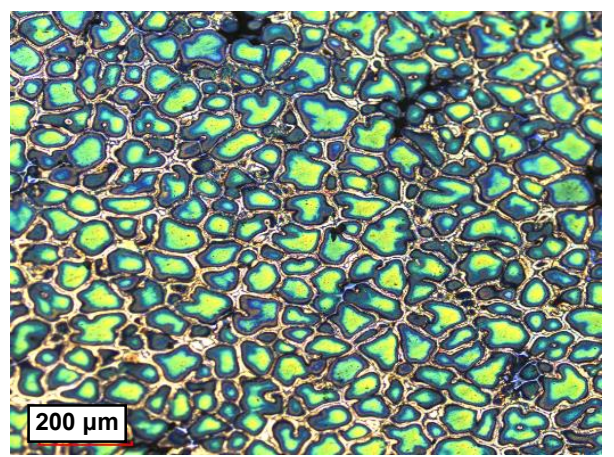

Figure 6 Microstructure of the alloy AICu4Mg1

0.3 wt $\%$ of AITi3B1, etched, sample 5

Figure 1 shows the microstructure of the AlCu4Mg1 alloy before and Figure 2 the microstructure after color etching. The situation is similar in Figure $\mathbf{3}$ and Figure 4, where it is also possible to observe the effect of heat treatment. The method of color metallography enables at quality level observe and document the present 
intermetallic phases and heterogeneity of chemical composition or crystal segregation within the dendritic cells. Individual colors tones after a cross-section of dendritic cell documenting the inhomogeneity of chemical composition. From the figures of microstructures is well illustrated in color heterogeneity of the chemical composition of dendritic cells and interdendritic space. After the heat treatment, it is possible to observe the dissolution of one or more phases in the solid solution. As a result of this treatment, chemical heterogeneity was also partially removed.

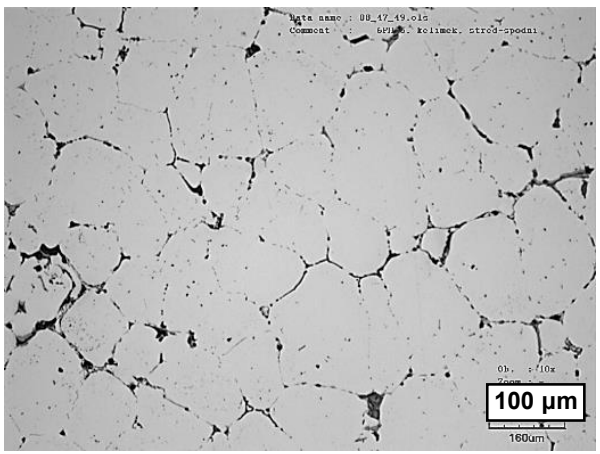

Figure 7 Microstructure of the alloy AlCu4Mg1, 0.3 wt $\%$ of AITi3B1, heat-treated, unetched, sample 6

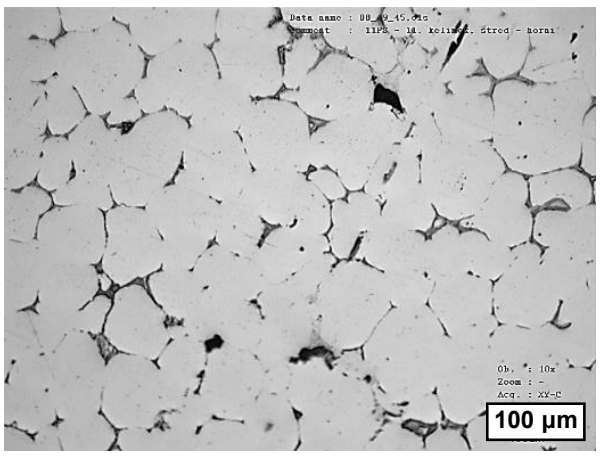

Figure 9 Microstructure of the alloy AlCu4Mg1 $3 \mathrm{wt} \%$ of AITi3B1, unetched, sample 11

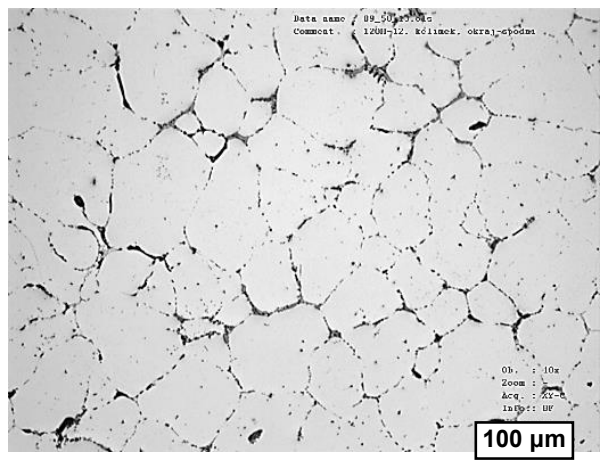

Figure 11 Microstructure of the alloy AICu4Mg1, 3 wt $\%$ of AITi3B1, heat-treated, unetched, sample 12

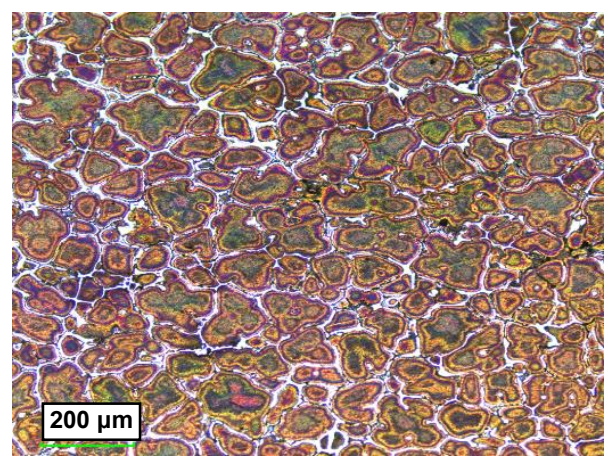

Figure 8 Microstructure of the alloy AlCu4Mg1, 0.3 wt\% of AITi3B1, heat-treated, etched, sample 6

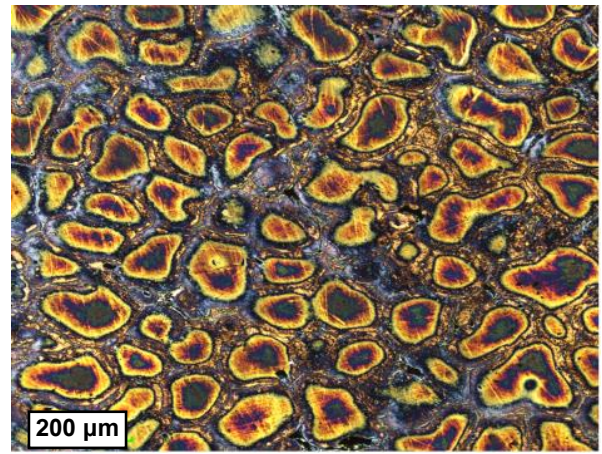

Figure 10 Microstructure of the alloy AICu4Mg1 3 wt\% of AlTi3B1, etched, sample 11

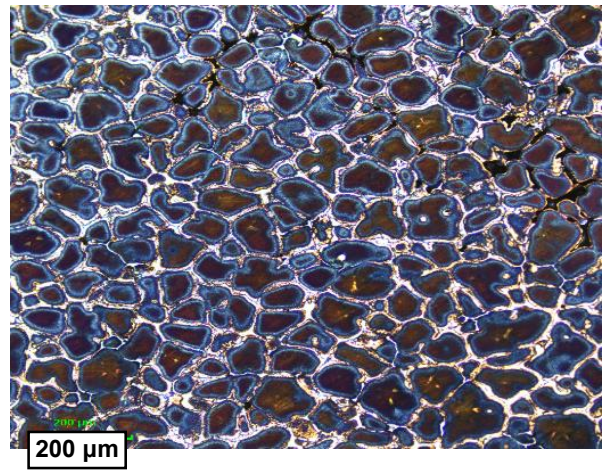

Figure 12 Microstructure of the alloy AlCu4Mg1, 3 wt\% of AITi3B1, heat-treated, etched, sample 12

Figure 5 shows the microstructure of the AlCu4Mg1 alloy before and Figure 6 the microstructure after color etching. In these figures, it is possible to observe the effect of the addition of AITI3B1 on the refinement of the structure $(0.3 \mathrm{wt} \%)$. Figures 7 and 8 then show the state of the structure in the unetched and etched state 
after heat treatment, where we can observe the dissolution of the intermetallic phases and the equalization of the chemical composition of the alloy and the uniformity of its structure. The same is for the alloy of the experimental sample in Figure 9 (unetched) and Figure 10 (etched), where the experimental samples with 3 wt\% of AITi3B1 inoculum content. Figures 11 and 12 then show the state of the structure after heat treatment.

\subsection{Evaluation using SEM and EDS (Electron Dispersive Spectroscopy) analysis}

To evaluate the effect of heat treatment on chemical heterogeneity, the AICu4Mg1 alloy was subjected to EDS analysis (area - Figure 13, Figure 14 A, point - Figure 14 B), which showed the distribution of aluminum as the base metal and individual alloying elements in a selected area of the AlCu4Mg1 alloy sample before and after heat treatment. Sample 6 is presented in the paper (AICu4Mg1, 0.3 wt\% of AITi3B1, heat-treated).

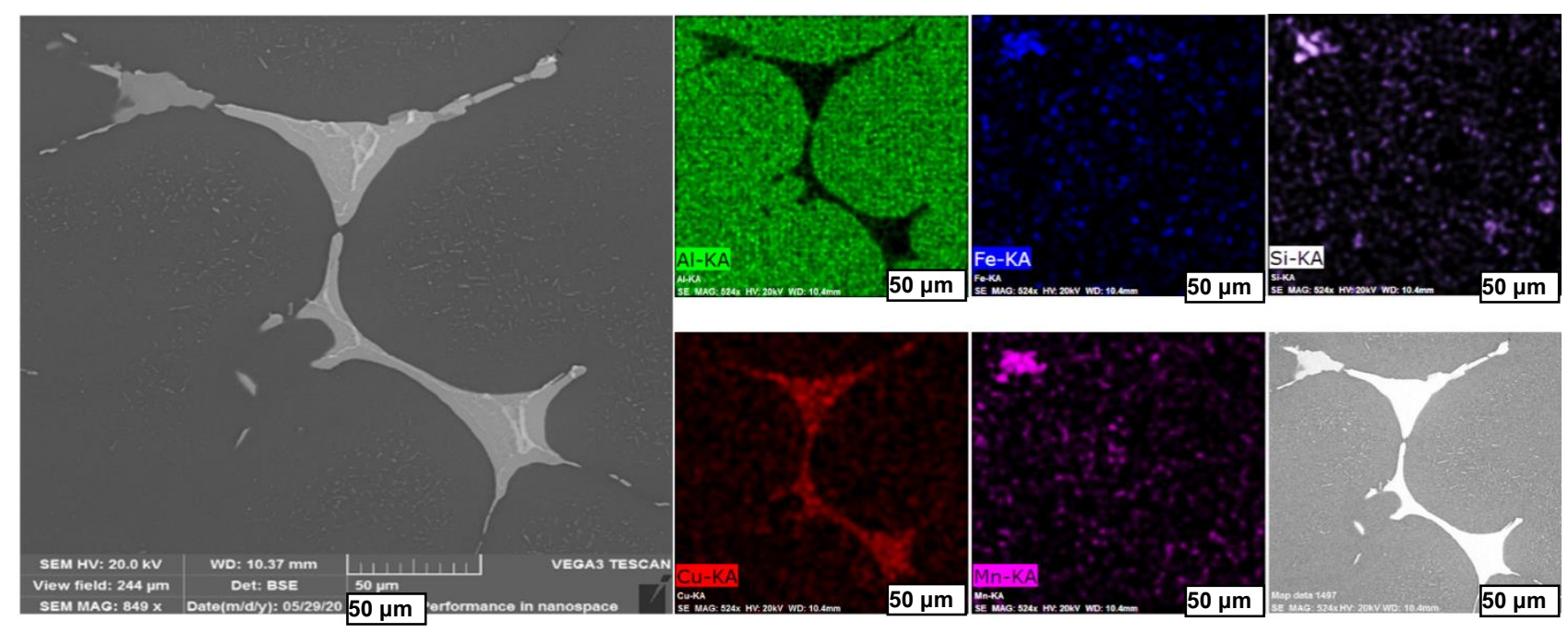

Figure 13 SEM and EDSof the alloy AICu4Mg1, 0.3 wt\% of AITi3B1, heat-treated, sample 6

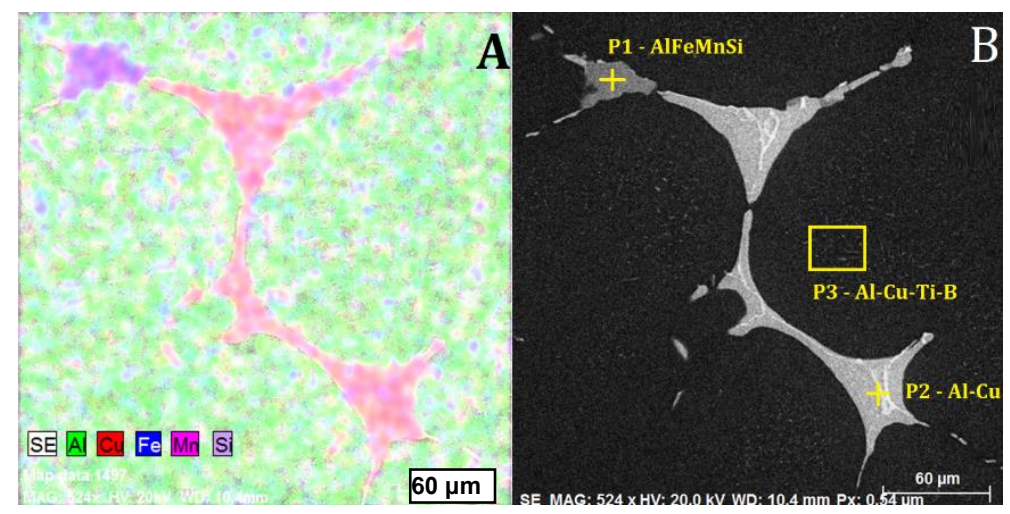

Figure 14 EDS of the alloy AICu4Mg1, 0.3 wt\% of AITi3B1, heat-treated sample 6

Table 2 EDS analysis of theAICu4Mg1 alloy, distribution of Al, Cu and other elements (wt\%)

\begin{tabular}{|c|c|c|c|c|c|c|c|c|}
\hline Element / Area & Al & $\mathbf{C u}$ & $\mathbf{S i}$ & $\mathbf{M g}$ & $\mathbf{F e}$ & $\mathbf{M n}$ & $\mathbf{T i}$ & $\mathbf{B}$ \\
\hline P1 & 81.05 & 5.58 & 3.41 & 0.63 & 4.02 & 5.31 & - & - \\
\hline P2 & 75.24 & 24.76 & - & - & - & - & - & - \\
\hline P3 & 83.85 & 3.66 & - & - & - & - & 0.06 & 6.93 \\
\hline
\end{tabular}

It is apparent from the concentration map Figure 13 and Figure $14 \mathrm{~A}$ of experimental alloy AICu4Mg1 that the aluminum distribution over the whole surface of dendritic cells is relatively uniform. From Figure 13 and 
Figure $14 \mathrm{~A}$, it can be seen the increased concentration of copper in the interdendritic spaces. From the distribution of the iron, manganese and silicon it can be seen that there is also the area in interdendritic space that was subsequently analyzed by EDS point method and points to the presence of a phase with elements listed below (Fe, Mn, $\mathrm{Si}$ ). Ti, B particles are also present in the structure, which are connected with AITi3B1 inoculation and are dispersed in $\alpha$ solid solution. Figure 14 B shows a point analysis of selected areas and the elemental composition of these areas is shown in Table 2.

\section{CONCLUSION}

The experimental work described in this paper is focused on the identification of chemical heterogeneity in the alloy EN AW-2024 (AlCu4Mg1). The structure of the alloy was influenced using AITi3B1 inoculant in different $w t \%$ amount and heat treatment (homogenization annealing).

Metallographically prepared experimental samples were examined to microstructure observation using an optical microscope. To investigate the heterogeneity of the structure, the samples were color etched before and after heat treatment. The method of color etching and subsequent analysis by optical microscopy is a very useful tool for evaluating the microstructure of the material. Nowadays, when methods such as SEM, XRD, TEM and others predominate, classical optical metallography still has its significance and its results often cannot be replaced by any of these methods. Both the effect of AITi3B1 on grain size and the effect of heat treatment was observed in the structure, which affected the chemical heterogeneity and caused the phases dissolution. Chemical heterogeneity strongly depends on the solidification rate of the alloy and was identified using the method of color metallography, which confirmed the considerable chemical heterogeneity of experimental alloys. Extensive segregation arising at these experimental alloys was confirmed also by energydispersive spectroscopy, when recorded concentration maps were rich in copper in interdendritic space. This method confirmed the presence of different phases, which caused the emergence of extensively crystal segregation and subsequently they were removed by homogenization annealing. In the AICu4Mg1 alloy, occurs mainly the binary eutectic $\alpha+\mathrm{CuAl}_{2}$ and a small amount of ternary eutectic $\alpha+\mathrm{CuAl}_{2}+\mathrm{S}\left(\mathrm{Cu}_{2} \mathrm{Mg}_{2} \mathrm{Al}_{5}\right)$. In addition to these basic components of the phases, there are other phases, namely $\mathrm{Mg}_{2} \mathrm{Si}, \mathrm{FeAl}_{3}, \mathrm{AlFeMnSi}$, AlCuFeMn.

\section{ACKNOWLEDGEMENTS}

\section{This article was created due to the project nr. 48101162009 - 4801 under the specific university research on FSI JEPU.}

\section{REFERENCES}

[1] MICHNA, Š, LUKÁČ, I. et al. Aluminum materials and technologies from A to Z. Adin s.r.o. Prešov, 2007.

[2] CIBULA, A. Themechanisms of grain refinement of sand castings in aluminum alloys. Journal of the Institute of Metals. 1949, vol. 76, pp. 321-360.

[3] SIGWORTH, G. K. The grain refining of aluminum and phase relation ships in the Al-Ti-B system. Metallurgical Transactions A. 1984, vol. 15, pp. 277-282.

[4] RAPPAZ, M., DANITZIG J.A. Solidification. EPFL Press. 2nd Edition, 2016.

[5] SVOBODOVA, J., HAJDÚCH, P. Quality analysis of AITi5B1 master alloy. Manufacturing Technology. 2017, vol. 17, no. 5, pp. 858-863.

[6] SKALICKÝ, I., BAJCURA, M., BORUSíK, R. Influence of various methods of melt mixing on the structure of semicontinual cast Al alloys. Engineering technology. 2018, vol. XXIII, no. 2, pp. 93-98. in Czech.

[7] WEISS, V., SVOBODOVÁ, J. The use of colour metallography and EDS for identification of chemical heterogeneity of selected aluminum alloys copper and zinc alloyed. Manufactruring Technology. 2015, vol. 15, no. 6, pp. 1048-1053.

[8] BROOK, G. B., BRANDES, E. A. Smithells Light Metals Handbook. Blutterworth-Heinemann, 1998 